\title{
O DESENVOLVIMENTO DA COMPETÊNCIA PARA O TRABALHO EM EQUIPE A DISTÂNCIA COM O USO DO METAVERSO SECOND LIFE ${ }^{\circledR}$
}

\author{
THE DEVELOPMENT OF DISTANCE TEAMWORK COMPETENCE THROUGH \\ THE USE OF THE SECOND LIFE ${ }^{\circledR}$ METAVERSE
}

Recebido em: 27/12/2012 - Aprovado em: 28/02/2013 Avaliado pelo sistema double blind review Editora Científica: Manolita Correia Lima

\begin{abstract}
ANA CLÁUDIA BILHÃO GOMES anaconsultrh@gmail.com AMAROLINDA ZANELA KLEIN

\author{
UNIVERSIDADE DO VALE DO RIO DOS SINOS
}

\section{RESUMO}

Com os avanços das Tecnologias da Informação e Comunicação (TIC), a Educação a Distância (EaD) vem apresentando um crescimento significativo e trazendo novos desafios, como o desenvolvimento de competências comportamentais requeridas pelo mercado de trabalho. Dentre elas, está a competência para o trabalho em equipe. Percebendo-se a necessidade de se explorar novas tecnologias que contribuam nesse sentido, o objetivo deste trabalho foi identificar se (e como) o uso da tecnologia metaverso (Mundos Digitais Virtuais em $3 \mathrm{D}$ ) pode colaborar para o desenvolvimento da competência para o trabalho em equipe na educação a distância na área de Gestão de Recursos Humanos. O método utilizado foi a Design Research e o artefato desenvolvido foi um método de capacitação no metaverso Second Lifeß. Uma equipe, composta por seis alunos voluntários, participou da pesquisa. Os alunos perceberam como possibilidades que a tecnologia metaverso oferece para o desenvolvimento da competência investigada: a construção de um contexto para o desenvolvimento da competência; a vivência de situações que propiciem às pessoas planejarem, agirem e interagirem; a possibilidade de aplicação de técnicas de gestão e atividades práticas; um espaço para o desenvolvimento das relações interpessoais. Em relação ao artefato desenvolvido (método de capacitação), os principais aspectos reconhecidos para melhorar foram: horários mais adequados para reuniões e mais tempo de interação. Sobre a tecnologia utilizada, identificaram-se não apenas diversas affordances educacionais do metaverso, mas também algumas dificuldades associadas ao seu uso. A pesquisa traz uma série de lições aprendidas com o uso dessa tecnologia, lições estas que podem ser úteis a outras aplicações semelhantes, buscando-se avançar nos recursos e métodos para o desenvolvimento de competências na Educação a Distância, na área de Administração.

Palavras-chave: competências; trabalho em equipe; metaverso.

\section{ABSTRACT}

With the developments in Information and Communication Technologies (ICT), Distance Education (DE) has spread and brought with it new challenges, such as the development of behavioral competencies required by the labor market, for example the competence for teamwork. Considering the need to explore new technologies that contribute to developing this competence, the goal of this study was to identify if and how the use of metaverse technology $(3 D$ Digital Virtual Worlds) can contribute to the development of teamwork competence in distance education, in the area of Human Resource Management. The method used was the Design Research and the artifact developed was a

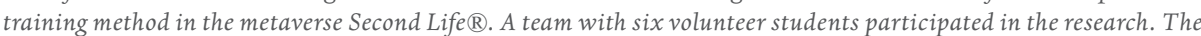
students perceived the following as the main metaverse technology affordances regarding the development of teamwork competence: the construction of a context for such development, the experience of situations allowing people to plan, act and interact, the ability to apply management techniques and practical activities, and the provision of a space for the development of interpersonal relationships. Regarding the artifact (training method), the main issues identified as requiring improvement were: more adequate time schedules for meetings and more interaction time. About the technology, several educational affordances of the metaverse were identified, as were some difficulties associated with its use. The research led to a series oflessons learned about the use of this technology, and these lessons may be useful to other similar applications when seeking to advance the methods and resources for the development of teamwork competence in Distance Education, in the area of Administration.

Keywords: competences; teamwork; metaverse. 


\section{INTRODUÇÃO}

Com os avanços das Tecnologias da Informação e Comunicação (TIC), a Educação a Distância $(\mathrm{EaD})$ vem apresentando um crescimento significativo no mundo e também no Brasil. No último Censo da Educação Superior, de 20I0, a EaD já correspondia a I4,6\% das matrículas de graduação no ensino superior no Brasil, sendo que no ano de 2000 representava menos de $\mathrm{I} \%$ (INEP, 2OII).

O aumento dos cursos de EaD traz novos desafios, entre os quais está o desenvolvimento de competências comportamentais requeridas pelo mercado de trabalho, em ambiente onde as interações ainda ocorrem, prioritariamente, de forma digital virtual e são mediadas, basicamente, pela tecnologia de base textual (SCHLEMMER; BACKES, 2008).

Uma dessas competências comportamentais mais importantes para qualquer profissional, e especialmente para os administradores, é a competência para o trabalho em equipe, ou seja, pessoas que interajam de forma interdependente para alcançar um objetivo comum (PARKER, I994, I995; MARGERISON; MCCANN, 1996; ELLIS, 2005). Em essência, ninguém trabalha sozinho, mas, algumas profissões como a de Recursos Humanos (RH), por exemplo, implicam significativamente a competência para o trabalho em equipe, pois envolve a gestão das pessoas em direção aos objetivos organizacionais.

Percebe-se, assim, a necessidade de se explorar novas tecnologias, que possam incrementar a relação interpessoal e o desenvolvimento de competências comportamentais - mesmo que à distância - para os alunos da área de Gestão de RH na EaD.

Nesse sentido, a tecnologia de Metaversos, que são os Mundos Digitais Virtuais em 3D, pode ser uma alternativa. A utilização dessa tecnologia ocorre via Internet e o acesso é gratuito para o usuário final, bastando fazer a instalação do software, por meio de download na página oficial e a criação do avatar (representação gráfica de um sujeito em um mundo digital virtual).

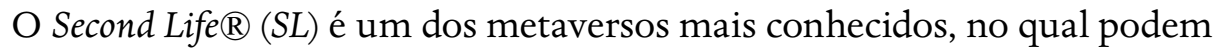


ser desenvolvidos ambientes simulados ou cópia muito similar de lugares que existem na realidade (BAINBRIGDE, 2007). O SL tem acesso gratuito ao usuário final em: www.secondlife.com.

Entretanto, a tecnologia de metaverso tem sido pouco explorada na EaD no Brasil. O último censo realizado pela Associação Brasileira de Educação a Distância (ABED) avaliou a implementação de diversos meios e recursos instrucionais nos cursos a distância, sendo que, em relação aos mundos digitais virtuais, $54 \%$ dos participantes disseram não aplicar esses recursos (CENSOEAD.BR, 2OII).

Diante da situação problemática acima relatada, percebeu-se um campo de conhecimento a ser explorado e definiu-se para esse estudo o seguinte objetivo: Identificar se e como o uso da tecnologia metaverso pode colaborar para o desenvolvimento da competência para o trabalho em equipe na educação a distância na Gestão de Recursos Humanos.

Para tanto, este artigo está estruturado da seguinte forma: nas duas próximas seções, explora-se a literatura a respeito de metaversos e da competência para o trabalho em equipe. Na sequência, apresentam-se o método de pesquisa, os resultados e a discussão, e, por fim, as considerações finais do artigo.

\section{A TECNOLOGIA METAVERSO E O SECOND LIFE}

A tecnologia metaverso é representada pela sigla MDV3D, que significa Mundos Digitais Virtuais em 3D ( $3^{\mathrm{a}}$ dimensão), que são acessados pelos usuários por meio da Internet. Esses ambientes tridimensionais possuem as características e os objetos semelhantes aos de ambientes reais, nos quais os usuários interagem na forma de avatares entre si e com o ambiente, e podem realizar diversas atividades como andar, correr, nadar ou mesmo se tele transportar ou voar (SCHLEMMER; BACKES, 2008).

Os MDV3D são dinâmicos, pois se modificam na medida em que os sujeitos interagem com eles. Nos meios digitais virtuais tradicionais o acesso à informação ocorre por meio de um browser, numa interface bidimensional, que utiliza principalmente textos e imagens estáticas. No metaverso a 
navegação transcorre num ambiente tridimensional, com o dinamismo de objetos virtuais, podendo manter também os textos, áudios e imagens (SCHLEMMER; TREIN; OLIVEIRA, 2008).

Bainbridge (2007) utiliza a expressão mundo digital virtual para descrever ambientes eletrônicos que podem imitar visualmente espaços físicos complexos, nos quais as pessoas - representadas pelos seus avatares - podem se comunicar umas com as outras e interagir com objetos virtuais. Os avatares utilizados no metaverso são criados pelos próprios usuários e permitem o estabelecimento de interações entre os mesmos, pois eles se comunicam e apresentam um corpo que faz parte do processo de interação com o ambiente e com as outras pessoas, ou seja, os outros avatares. A interação ocorre por meio de uma perspectiva de primeira pessoa, portanto, gera a noção de presença (LOMBARD; DitTON, 1997).

Nesse espaço são encontrados locais de trabalho, lazer, cultura, educação e todo tipo de atividade social, assim como é possível desenvolver ambientes com as características desejadas, por mais inusitadas que sejam. Portanto, o metaverso pode ser utilizado como um laboratório para diferentes interesses de pesquisa. Bainbridge (2007) alega que os experimentos das ciências sociais e econômicas têm visto na Internet uma alternativa de ampliar o escopo de suas pesquisas, e espera-se que os $\mathrm{MDV}_{3} \mathrm{D}$ ofereçam essa oportunidade, em função das affordances possíveis.

Dentro do contexto de um ambiente virtual $3 \mathrm{D}$, affordances podem ser definidas como as propriedades de recurso entre um artefato e um ator (ou seja, a maneira como um usuário interage com um objeto) e as possibilidades que são vislumbradas pelo usuário com o uso desse objeto (ANDREAS et al., 20IO).

Girvan e Savage (2010) focam especificamente na abordagem educacional, na qual as affordances seriam as características de um artefato ou tecnologia que determinam se e como um comportamento particular de aprendizagem pode eventualmente ocorrer dentro de um determinado contexto. As affordances percebidas podem variar entre os usuários.

Collins (2008) menciona que as affordances da plataforma metaverso dão aos estudantes a capacidade de fazer coisas que ainda não existam ou não possam 
ser feitas na vida real, podendo constituir uma aprendizagem autêntica. Outras possibilidades específicas dos metaversos, como a comunicação e o movimento, são affordances percebidas como educativas, que emergem por meio da implementação de uma atividade de aprendizagem construtivista.

Em adição, Waborton (2009) identificou alguns pontos em que a vivência no $S L$ pode trazer inovação para a prática pedagógica: o estímulo ao entrosamento social entre indivíduos e entre indivíduos e objetos; a recriação ou simulação de contextos difíceis ou impossíveis de serem acessados de forma real; a imersão em um ambiente $3 \mathrm{D}$, onde a sensação de presença e pertencimento facilita o compartilhamento de um propósito e, logo, o processo de ensino e aprendizagem.

No estudo de Andreas et al. (20I0), a equipe de investigação realizou suas atividades em espaços educativos, na forma de avatares, utilizando-se das ferramentas para a comunicação não verbal e visualização disponíveis nesse ambiente e concluíram que o SL pode complementar e/ou aumentar as interações face a face, melhorando abordagens em colaboração a distância e a comunicação entre os envolvidos.

Collins (2008) considera que o ensino superior tem um papel fundamental a desempenhar no desenvolvimento do uso dos mundos virtuais. Em função disso, muitas universidades já se instalaram no Second Life $®$, mantendo "ilhas" nas quais realizam atividades educativas. Até mesmo congressos, como o Slactions (http://www.slactions.org/), ocorrem periodicamente dentro de metaversos, reunindo pessoas de diversos países para a troca de conhecimentos sobre o uso de metaversos com diversas finalidades, especialmente para a educação.

Com base na apresentação dos metaversos e das possíveis contribuições para a aprendizagem a distância e para o desenvolvimento de competências, na seção a seguir, esta última temática é aprofundada com ênfase na competência para o trabalho em equipe.

\section{COMPETÊNCIA PARA O TRABALHO EM EQUIPE}

Considerando os diferentes conceitos sobre competências existentes na literatura, nesta pesquisa, adotou-se a seguinte definição de competências: 
competência é a capacidade de mobilizar saberes, demonstrar habilidades e ter atitudes adequadas, para, diante de uma situação-problema, encontrar uma solução adequada para aquele contexto específico, e, por meio de uma ação eficaz, atingir o resultado esperado. Representa um processo contínuo de aprendizagem e desenvolvimento (PARRY, I996; ZARIFIAN, 200I; LE BOTERF, 2003; PERRENOUD, I999; PERRENOUD; THURLER, 2002).

Alguns autores fazem referência ao conceito de competência em nível de equipes e grupos de trabalho. Zarifian (200I) alega que em cada grupo de trabalho se manifesta uma competência coletiva, que representa mais do que o somatório das competências de seus membros. Isso ocorre em função da sinergia entre as competências individuais e as interações sociais existentes no grupo. Le Boterf (2003) corrobora ao ressaltar que as competências coletivas emergem da cooperação, das trocas e articulações estabelecidas entre as competências individuais dos componentes da equipe.

Como os conceitos pesquisados revelam, as competências podem ser individuais ou coletivas; porém, destaca-se que este artigo se concentra na competência individual, ou seja, na capacidade do indivíduo para trabalhar em equipe, apesar da construção dessa competência ser coletiva e da manifestação da mesma ocorrer na interação com o grupo. Zarifian (200I, p. II5) diz que "a competência individual, ainda que ela se manifeste em relação a um indivíduo claramente identificado, e se expresse no que ele faz, é efetivamente [...] o resultado de numerosas trocas de saberes e de numerosas conexões entre atividades diferentes".

O trabalho em equipe é considerado chave na administração moderna; portanto, capacitar as pessoas para trabalharem bem, juntas, passa a ser função elementar de todo administrador (MARGERISON; MCCANN, I996).

Algumas das principais vantagens do trabalho em equipe apontadas pelos autores que se dedicam a essa temática são: a qualidade superior do trabalho, resultados melhores, mais habilidades individuais têm chance de ser reveladas, flexibilidade e capacidade de adoção de mudanças (PARKER, 1994, 1995; ROBBINS; FINLEY, I997; JEZERSKYTE்; ŽYDŽIÜNAITÉ, 2005; STAGGERS; GARCIA; NAGELHOUT, 2008).

Apesar de serem apresentados diversos benefícios e vantagens do trabalho em equipe, Robbins e Finley (1997) alertam que nem sempre as equipes 
funcionam. Moscovici (2008) alega que, apesar de os termos "grupo" e "equipe" frequentemente serem utilizados como sinônimos, grupos existem em todas as organizações, mas equipes seriam raras, pois em uma equipe haverá: objetivos comuns, engajamento, compartilhamento, comunicação aberta, confiança, assunção de riscos, respeito, cooperação e busca de desenvolvimento constante.

Moscovici (2008) complementa: "Um grupo que se desenvolve como equipe necessariamente incorpora a sua dinâmica às habilidades de diagnose e de resolução de problemas". Ou seja, uma equipe é capaz de diagnosticar e buscar a solução para os seus próprios problemas, e, em função disso, se distingue e consolida. (MOscovicI, 2008, p. 5-6)

Os grupos de trabalho interagem para o compartilhamento de informações e a tomada de decisões para o desempenho de suas áreas de atuação, quando necessário; já as equipes geram sinergia positiva e, por meio de seus esforços individuais, resultam em desempenhos superiores que a soma da contribuição dos indivíduos (STAGGERS; GARCIA; NAGELHOUT, 2008; ROBBINS, 2009).

Equipes, portanto, são formadas por pessoas que colaboram de forma interdependente, que interagem significativamente com os outros para alcançar metas específicas de desempenho, incluindo resultados produtivos, a satisfação pessoal e a capacidade de se adaptar e aprender. Além disso, os membros de uma equipe partilham a responsabilidade pelo resultado de suas atribuições (PARKER, 1994, I995; STEYN; STEYN, 2009).

Para Katzenbach e Smith (1993), uma equipe seria constituída de poucas pessoas com competências complementares, comprometidas com um propósito comum, estabelecendo metas de desempenho e formas de trabalho, pelas quais são mutuamente responsáveis.

Em complemento, Griffin e Moorhead (2006) apontam que, normalmente, as equipes se compõem de pessoas com três tipos de capacidades: a) capacidade técnica ou funcional para realizar as funções; b) capacidade de resolver problemas ou tomar decisões, e; c) habilidades interpessoais para administrar a comunicação, resolver conflitos, orientar as ações, dar apoio e reconhecer os interesses dos demais integrantes da equipe. Nem todos 
terão todas as competências exigidas, mas irão desenvolvendo-as com o amadurecimento da equipe.

Considerando que há constante mudança de membros nas equipes, há uma necessidade de competências que sejam "transportáveis" entre as equipes e as tarefas. Ellis (2005) identificou cinco categorias genéricas de competências das equipes: a) a resolução de conflitos; b) a resolução de problemas; c) a comunicação; d) a fixação de metas e gestão de desempenho, e; e) o planejamento e a coordenação de tarefas.

Já que esse estudo envolve o desenvolvimento da competência para o trabalho em equipe em um ambiente virtual, é relevante o trabalho de Hertel, Konradt e Voss (2006), que argumentam que o nível de virtualidade é apenas uma dimensão das equipes, portanto, deve se considerar uma sobreposição das competências para as equipes convencionais e virtuais. Esses autores destacam a competência de autogestão como um aspecto particularmente relevante para as equipes com alto grau de virtualidade, nas quais há baixo controle e apoio por parte dos supervisores e/ou colegas de trabalho.

Como na revisão da literatura realizada não foi localizado um único conceito que abarcasse toda a complexidade do assunto aqui apresentado, a competência individual para o trabalho em equipe é aqui definida da seguinte forma: Trabalhar em equipe é ser capaz de se dedicar a um propósito comum. Envolve saber trabalhar de forma conjunta, reconhecendo que as pessoas possuem habilidades complementares. É participar da definição de metas e formas de trabalho e realizar o que the compete com autonomia e compromisso. Implica em saber se relacionar, saber se comunicar e participar da identificação e solução dos problemas em comum, apoiando e reconhecendo os esforços. Requer flexibilidade, adaptação e mudança, bem como a busca de desenvolvimento e aprendizado contínuo, tanto individualmente como de forma coletiva.

A operacionalização do construto trabalho em equipe foi realizada por meio da identificação de uma série de capacidades que compõem essa competência, conforme é apresentado no Quadro I. Tal construto foi considerado para avaliar o desenvolvimento da competência para trabalho em equipe na prática. 
Quadro I Capacidades da competência individual para o trabalho em equipe

\begin{tabular}{|c|c|}
\hline Capacidade de & Autores \\
\hline Dedicar-se a um propósito comum & $\begin{array}{l}\text { Katzenbach e Smith (1993); Parker (1995); } \\
\text { Jezerskytė e Žydžiünaitè (2005); Moscovici (2008) }\end{array}$ \\
\hline $\begin{array}{l}\text { Saber trabalhar em conjunto, cooperar e cola- } \\
\text { borar }\end{array}$ & $\begin{array}{l}\text { Parker (1995); Robbins e Finley (1997); Perrenoud } \\
\text { (2000); Jezerskytė e Žydžiünaitè (2005); Mosco- } \\
\text { vici (2008); Robbins (2009) }\end{array}$ \\
\hline $\begin{array}{l}\text { Reconhecer as habilidades dos outros, perce- } \\
\text { bendo-as como complementares às suas }\end{array}$ & $\begin{array}{l}\text { Parker (1995); Robbins e Finley (1997); Perrenoud } \\
\text { (2000); Moscovici (2008); Robbins (2009) }\end{array}$ \\
\hline $\begin{array}{l}\text { Participar do estabelecimento de metas de } \\
\text { desempenho e formas de trabalho conjuntas }\end{array}$ & $\begin{array}{l}\text { Katzenbach e Smith (1993); Parker (1995); Perre- } \\
\text { noud (2000); Ellis (2005); Moscovici (2008); Steyn } \\
\text { e Steyn (2009) }\end{array}$ \\
\hline $\begin{array}{l}\text { Realizar as tarefas que lhe cabem, com autono- } \\
\text { mia e compromisso com a equipe }\end{array}$ & $\begin{array}{l}\text { Katzenbach e Smith (1993); Parker (1994); Par- } \\
\text { ker (1995); Robbins e Finley (1997); Perrenoud } \\
\text { (2000); Jezerskytè e Žydžiünaitė (2005); Griffin e } \\
\text { Moorhead (2006); Hertel, Konradt e Voss (2006); } \\
\text { Steyn e Steyn (2009) }\end{array}$ \\
\hline $\begin{array}{l}\text { Saber se relacionar (ter empatia, respeito às dife- } \\
\text { renças e diversidade, lidar com conflitos) }\end{array}$ & $\begin{array}{l}\text { Parker (1995); Robbins e Finley (1997); Perrenoud } \\
\text { (2000); Ellis (2005); Jezerskytè e Žydžiünaitè } \\
\text { (2005); Hertel, Konradt e Voss (2006); Moscovici } \\
\text { (2008) }\end{array}$ \\
\hline $\begin{array}{l}\text { Saber se comunicar (ser aberto ao diálogo, } \\
\text { expressar opiniões, saber escutar) }\end{array}$ & $\begin{array}{l}\text { Parker (1995); Robbins e Finley (1997); Ellis (2005); } \\
\text { Griffin e Moorhead (2006) }\end{array}$ \\
\hline $\begin{array}{l}\text { Participar da identificação e solução dos proble- } \\
\text { mas da equipe }\end{array}$ & $\begin{array}{l}\text { Robbins e Finley (1997); Perrenoud (2000); Griffin } \\
\text { e Moorhead (2006); Moscovici (2008); Robbins } \\
\text { (2009); Steyn e Steyn (2009) }\end{array}$ \\
\hline $\begin{array}{l}\text { Dar apoio, encorajar e reconhecer os esforços } \\
\text { dos membros da equipe }\end{array}$ & $\begin{array}{l}\text { Robbins e Finley (1997); Losoncy (1997); Griffin e } \\
\text { Moorhead (2006); Hertel, Konradt e Voss (2006); } \\
\text { Moscovici (2008) }\end{array}$ \\
\hline $\begin{array}{l}\text { Ter flexibilidade, ser capaz de se adaptar e mudar, } \\
\text { se necessário }\end{array}$ & $\begin{array}{l}\text { Parker (1994); Parker (1995); Robbins e Finley } \\
\text { (1997); Jezerskytè e Žydžiünaitè (2005); Steyn e } \\
\text { Steyn (2009) }\end{array}$ \\
\hline $\begin{array}{l}\text { Buscar o autodesenvolvimento e o autoapren- } \\
\text { dizado }\end{array}$ & $\begin{array}{l}\text { Griffin e Moorhead (2006); Hertel, Konradt e Voss } \\
\text { (2006); Moscovici (2008) }\end{array}$ \\
\hline $\begin{array}{l}\text { Colaborar para o desenvolvimento e aprendi- } \\
\text { zado da equipe }\end{array}$ & $\begin{array}{l}\text { Robbins e Finley (1997); Griffin e Moorhead } \\
\text { (2006); Moscovici (2008) }\end{array}$ \\
\hline
\end{tabular}




\section{MÉTODO DE PESQUISA}

O método de pesquisa utilizado foi a Design Research (DR), que é um tipo de investigação que se constitui basicamente na atividade de construção, na qual ocorre o processo de criação de artefatos, e a atividade de avaliação desses artefatos de acordo com a sua utilidade (MARCH; SMITH, 1995). Este método possui as seguintes etapas, de acordo com Vaishnavi e Kuechler (2005): a) Conscientização do problema; b) Sugestões; c) Desenvolvimento; d) Avaliação, e; e) Conclusão. Por tratar-se de um método de pesquisa pouco utilizado na área de Administração, será apresentado detalhadamente a seguir.

Passo 1-Conscientização do Problema: Conforme Vaishnavi e Kuechler (2005) esta etapa é o início da pesquisa de DR, quando o pesquisador se sensibiliza com um problema, coletando dados sobre ele, baseados em diversas fontes.

Nesta etapa, foi elaborada uma revisão da literatura e se entrevistou, apoiado em roteiro semiestruturado, a coordenação de curso, três professores e quatro alunos do contexto de pesquisa (curso de Gestão de RH da Unisinos - Universidade do Vale do Rio dos Sinos - RS). A escolha dos entrevistados nesta etapa foi por conveniência (acessibilidade), respeitando os critérios de vinculação ao curso de Gestão de RH e à modalidade de educação a distância.

O propósito dessas entrevistas foi compreender como, até então, vinha sendo desenvolvida a competência para o trabalho em equipe no contexto pesquisado.

Como principais resultados dessa etapa, de forma sumarizada, verificouse que a plataforma utilizada para $\mathrm{EaD}$, no curso (Moodle), apresentava uma série de restrições para o desenvolvimento de competências comportamentais, como a competência para o trabalho em equipe, já que essa plataforma basicamente vale-se de texto como recurso principal para interação. Da mesma forma, verificou-se não haver metodologias específicas para o desenvolvimento da competência visada. Em geral adotam-se trabalhos em grupo (dependendo da iniciativa de cada professor) e as ferramentas atualmente disponíveis são limitadas para acompanhar como 
esses trabalhos em grupo se desenvolvem nos "bastidores", o que limita a avaliação do desenvolvimento da competência para trabalhar em equipe.

De posse dessa análise, ao final desse passo do método houve condições de elaborar uma proposta de artefato.

Passo 2 -Sugestões: Essa é a fase em que o pesquisador levanta uma ou mais tentativas de design, alinhadas à proposta de pesquisa, visando uma concepção de artefato preliminar consistente (VAISHNAVI; KUECHLER, 2005). Lembrando que o objetivo era desenvolver uma solução para o desenvolvimento da competência para trabalho em equipe a distância, no curso pesquisado.

Inicialmente pensou-se em realizar uma dinâmica de grupo no ambiente do metaverso Second Life $\AA$, com o uso da técnica do Tangram. Os alunos seriam desafiados em grupo a montar figuras baseadas em peças desenvolvidas na forma de objetos no metaverso. Porém, a ideia foi descartada por ser considerada pouco complexa e possivelmente muito rápida de ser realizada. Em função disso, a interação entre os participantes seria breve e pontual, inviabilizando que os alunos se empenhassem em um desafio, que os levasse a trabalhar em equipe de forma semelhante ao que de fato é necessário em um ambiente real de trabalho.

Com base nisso, passou-se a pensar em algo que fosse mais arrojado e envolvesse uma interação mais intensa, como um desafio que gerasse um resultado, que fosse instigante ao grupo de alunos, uma simulação que os aproximasse de algo de sua realidade profissional. Foi então que se pensou na realização de um evento, para o público de Recursos Humanos, e elaborou-se o plano inicial de sugestão do artefato, que implicaria em desafiar os alunos a realizarem o $\mathrm{I}^{\circ}$ Encontro de Profissionais e Estudantes de Recursos Humanos no Second Life®.

Essa atividade foi considerada adequada, pois para realizar o evento os alunos teriam diversas interações entre si por meio de reuniões para planejarem, organizarem e operacionalizarem o encontro. Além disso, teriam que interagir com outras pessoas convidando-as a participar da atividade. Os alunos também lidariam com situações muito similares às de uma equipe que interage presencialmente, ou seja, teriam que se comunicar, 
cooperar, assumir responsabilidades, negociar, lidar com conflitos e tomar decisões em conjunto.

Logo, o artefato configurou-se então em um método de capacitação para o desenvolvimento da competência individual do trabalho em equipe, com o uso da tecnologia metaverso. O método desenvolvido (artefato) é composto por:

1. Ambiente modelado no metaverso Second Life $®$ para a realização da capacitação: desenvolveu-se um ambiente modelado especificamente para a realização das atividades de capacitação para o trabalho em equipe, contendo: salas de reuniões, quadros, painéis, um auditório de evento e demais objetos. Esses ambientes simulavam o contexto real da Unisinos.

2. Treinamento para utilização do metaverso Second Lifeß: foi criado um treinamento específico para os participantes dessa capacitação aprenderem a utilizar esse software.

3. Instrumentos para diagnóstico da competência para trabalho em equipe: foi desenvolvida, com base na revisão da literatura, uma escala para a autoavaliação diagnóstica dos alunos em relação ao estágio de desenvolvimento da competência para trabalhar em equipe. Este instrumento utiliza uma escala Likert de 5 pontos para auto- avaliação do grau de desenvolvimento dos atributos da competência para trabalho em equipe, e seu objetivo é gerar reflexão, nos próprios aprendizes, sobre como se percebem em relação à competência visada para o desenvolvimento;

4. Reuniões de trabalho em equipe: foram criadas 05 (cinco) reuniões de trabalho com os alunos dentro do metaverso Second Life $囚$, as quais são a parte central da capacitação, pois cada uma delas possui objetivos específicos a serem alcançados, por meio do trabalho em equipe, isto é, nessas reuniões, o método previa o desenvolvimento dessa competência pelos participantes, na prática. Nessas reuniões, os participantes prepararam o " $\mathrm{I}{ }^{\circ}$ Encontro de Profissionais e Estudantes de RH no Second Life".

5. Evento: essa era a atividade final prevista no método de capacitação, 
que constituía a grande entrega do trabalho em equipe, desenvolvido ao longo das reuniões de trabalho.

6. Avaliação final: inclui a reaplicação da escala, para a autoavaliação dos alunos, em relação ao estágio de desenvolvimento da competência para trabalhar em equipe, Foi desenvolvido também para esse momento um questionário (com questões qualitativas), aplicado aos alunos participantes, ao final das atividades, e a professores que participaram do evento (Encontro de RH), que também foram entrevistados como forma de avaliação do método de capacitação desenvolvido e de seus resultados.

Passo 3-Desenvolvimento: Nesse passo da Design Research houve a aplicação do artefato, ou seja, o método de capacitação (VAISHNAVI; KUECHLER, 2005).

Os participantes da capacitação foram selecionados da seguinte forma: por meio de indicação das coordenadoras do curso de $\mathrm{RH}$ (EaD e presencial), levantou-se uma lista de alunos com potencial para participar da pesquisa, sendo que eles foram chamados a participar voluntariamente por meio de um convite para uma reunião de apresentação da pesquisa, que ocorreu em setembro de 20Ir. Dos 30 (trinta) alunos convidados, I2 (doze) compareceram. Desses, 8 (oito) alunos demonstraram interesse, porém, depois do início das atividades apenas 6 (seis) alunos permaneceram até o final.

Apesar do baixo número de participantes, estes constituíram uma equipe de trabalho, que é a unidade principal necessária para aplicação do artefato, permitindo, com isso, a avaliação do seu funcionamento na prática. A quantidade de participantes foi considerada adequada devido ao caráter qualitativo e exploratório do estudo, bem como à complexidade da pesquisa, ou seja, os participantes eram aprendizes no processo de capacitação, dedicando-se voluntariamente às atividades.

O perfil dos alunos que participaram de toda a capacitação teve a seguinte configuração: dois do gênero masculino e quatro do feminino, idade média de 25 anos, dois alunos da modalidade de ensino EaD e quatro do curso presencial.

Nesta etapa (aplicação do método de capacitação), utilizaram-se diversos tipos de coleta de dados, destacam-se: filmagem dos encontros realizados 
dentro do Second Life $($; gravação dos chats (também realizados dentro do

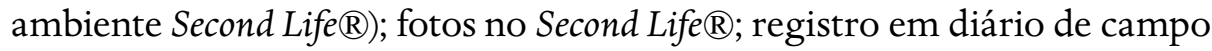
(observação-participante); registros nos diários de aprendizagem dos alunos, mensagens trocadas na equipe e com os pesquisadores.

Após o desenvolvimento das atividades planejadas, o próximo passo do método de pesquisa (Design Research) implica em avaliar o que foi realizado, identificando o conhecimento obtido por meio do artefato ou visando sugerir melhorias ao mesmo (VAISHNAVI; KUECHLER, 2005).

Passo 4 - Avaliação: As formas de avaliação implicaram tanto em avaliar a aprendizagem quanto em avaliar o artefato (método de capacitação) e são expostas de maneira sumarizada no Quadro 2.

Quadro 2 Formas de avaliação do método de capacitação

\begin{tabular}{|c|c|c|c|}
\hline 0 que foi avaliado & Quem avaliou & Como foi avaliado & $\begin{array}{l}\text { Quando foi } \\
\text { avaliado }\end{array}$ \\
\hline $\begin{array}{l}\text { Avaliação da aprendi- } \\
\text { zagem } \\
\text { O estágio de desenvol- } \\
\text { vimento da competên- } \\
\text { cia para o trabalho em } \\
\text { equipe }\end{array}$ & $\begin{array}{l}\text { Os alunos (6) se } \\
\text { autoavaliaram } \\
\text { A facilitadora } \\
\text { (pesquisadora } \\
\text { principal da } \\
\text { pesquisa) }\end{array}$ & $\begin{array}{l}\text { - A partir de instrumentos } \\
\text { específicos de autoavaliação } \\
\text { (escala) } \\
\text { - Por meio de momento de } \\
\text { avaliação e feedback ao } \\
\text { longo da capacitação }\end{array}$ & $\begin{array}{l}\text { No início, durante e } \\
\text { ao final do método } \\
\text { de capacitação }\end{array}$ \\
\hline \multirow{3}{*}{$\begin{array}{l}\text { Avaliação do artefato } \\
\text { (método de capacita- } \\
\text { ção) } \\
\text { Como a tecnologia } \\
\text { metaverso pode cola- } \\
\text { borar para o desenvol- } \\
\text { vimento da competên- } \\
\text { cia para o trabalho em } \\
\text { equipe }\end{array}$} & Os alunos (6) & $\begin{array}{l}\text { - Questionário ao final da } \\
\text { capacitação } \\
\text { - Feedbacks durante a } \\
\text { capacitação }\end{array}$ & $\begin{array}{l}\text { Durante e ao final } \\
\text { do método de } \\
\text { capacitação }\end{array}$ \\
\hline & A pesquisadora & $\begin{array}{l}\text { - Com base na análise dos } \\
\text { dados coletados }\end{array}$ & $\begin{array}{l}\text { Do início ao final } \\
\text { do método de } \\
\text { capacitação }\end{array}$ \\
\hline & $\begin{array}{l}\text { Professores (4) } \\
\text { participantes do } \\
\text { Encontro de } \mathrm{RH}\end{array}$ & $\begin{array}{l}\text { - Com base na entrevista após } \\
\text { o evento }\end{array}$ & $\begin{array}{l}\text { Após a aplicação } \\
\text { do método de } \\
\text { capacitação }\end{array}$ \\
\hline
\end{tabular}

Passo 5 - Conclusão - Nessa fase da Design Research os resultados são consolidados e registrados. São considerados como resultados: os construtos, os modelos, os métodos e as instanciações, de acordo com March e Smith (1995). 
Nesta pesquisa, esse passo representa os achados principais da aplicação do método de capacitação, sendo, portanto, a fase em que os resultados são apresentados e discutidos.

Após a coleta dos dados em cada passo do método, adotou-se um procedimento analítico geral para lidar com o grande volume de dados coletados (MILEs; huberman, 1994). A principal técnica de análise de dados utilizada nessa pesquisa foi a análise qualitativa (CRESwell, 2007). Para a organização e análise dos dados coletados foi utilizado o Software NVivo 9.

Na seção seguinte, apresentam-se os resultados da aplicação do artefato e sua avaliação. 


\section{APRESENTAÇÃO DOS RESULTADOS: O MÉTODO DE CAPACITAÇÃO APLICADO NO METAVERSO SECOND LIFE ® (SL)}

\section{TREINAMENTO DOS ALUNOS PARA O USO DO SL}

Esse treinamento ocorreu a distância em outubro de 20II, com duração de 3 h, usando como tecnologia de mediação o próprio $S L$ e o suporte extra por meio de chat no MSN Messenger. Os alunos receberam previamente um material com as explicações e os tutoriais básicos sobre como instalarem o programa e criarem o seu avatar. Desta forma, alguns já haviam visitado o ambiente e foram para a capacitação com alguma familiaridade com a tecnologia utilizada.

Registraram-se alguns problemas técnicos relacionados ao áudio, assim a comunicação teve que ser realizada por intermédio de chat (bate-papo virtual). Os alunos foram estimulados a interagir fora dos horários de reunião, para que pudessem ajudar uns aos outros a tirar maior proveito das possibilidades do metaverso. De modo geral, o treinamento atendeu ao seu objetivo e, ao final, os alunos foram capazes de utilizar as funcionalidades básicas do metaverso.

\section{AUTOAVALIAÇÃO DIAGNÓSTICA DOS ALUNOS}

Depois do treinamento para o uso do metaverso, os participantes da capacitação responderam a um questionário, com a intenção de se levantar as percepções dos mesmos em relação ao seu estágio atual de desenvolvimento da competência para o trabalho em equipe. Os alunos também listaram seus pontos fortes e os aspectos que consideravam poder melhorar em relação à competência para trabalhar em equipe.

Entre os pontos fortes, mencionaram: autoconhecimento; comunicação; gostar de interagir; liderança; vontade de colaborar e comprometimento com as tarefas. Como aspectos a melhorar mencionaram: ansiedade; timidez; insegurança; dificuldades na resolução de conflitos, em expressar sentimentos e lidar com diferenças. Isso serve para evidenciar como os alunos percebem que o desenvolvimento da competência para trabalhar em 
equipe está associado a aspectos comportamentais, ou seja, à capacidade de se relacionar, se comunicar e lidar com as suas emoções.

\section{REUNIÕES DE TRABALHO}

As reuniões de trabalho tinham como objetivo principal o desenvolvimento da competência individual dos alunos, para o trabalho em equipe, durante o processo de organização do evento no ambiente do SL. Para cada encontro havia uma pauta definida e, ao final da reunião, os alunos fariam um plano de ação e registros sobre como decorreu o trabalho, bem como as lições aprendidas, nos seus diários individuais de aprendizagem.

Além do treinamento inicial, ocorreram 5 (cinco) reuniões, às quintasfeiras, no horário das $23 \mathrm{~h}$ às ohzomin aproximadamente, sendo o único horário possível de conciliar para que todos pudessem participar, já que os alunos trabalhavam durante o dia e tinham aula à noite.

Como a participação no evento de capacitação era voluntária e em um horário pouco convencional, passou-se a utilizar outro meio, além do metaverso, para estimular os alunos a participarem e manterem uma comunicação contínua com eles, bem como guardar os registros para os fins de pesquisa. Para tanto, a estratégia utilizada foi a comunicação por e-mail.

Todas as reuniões de trabalho aconteceram a distância, em um ambiente modelado especialmente para a realização deste estudo. A sala de reuniões, em que os alunos se encontravam, localizava-se no espaço destinado ao PPG de Administração, na ilha da Unisinos, no Second Life. Durante as reuniões, os alunos tinham que tomar várias decisões em relação ao evento que realizariam, entre elas: o tema da palestra, o palestrante, os convidados, os meios de divulgação e todos os recursos necessários (auditório, brindes, banners, etc.). A facilitadora atuava na mediação, fazia os registros em diários de campo e lembrava os alunos sobre as suas responsabilidades, entre as quais estavam os registros no diário de aprendizagem.

As principais dificuldades durante a realização das reuniões estiveram associadas às questões tecnológicas. Nem todos os alunos podiam acessar, no horário das reuniões, equipamentos com hardware e software adequados para acesso ao SL, que demanda um computador preferencialmente com 
placa gráfica e com conexão de banda larga. O SL também estava passando por atualizações e, eventualmente, havia instabilidade na transmissão de áudio.

O horário tardio de realização das reuniões (em torno das $23 \mathrm{~h}$ ) também foi um fator dificultador; porém, como já foi explicado, este era o único horário disponível. As informações coletadas e as observações realizadas proporcionaram um conjunto de lições úteis aos fins da pesquisa.

O Quadro 3 demonstra de forma sintetizada as principais atividades realizadas e seus objetivos, bem como as lições aprendidas por meio do método de capacitação (artefato). Essas lições estão relacionadas tanto ao desenvolvimento da competência investigada, quanto ao uso da tecnologia metaverso.

Quadro 3 Síntese das atividades realizadas e lições aprendidas durante a capacitação

\begin{tabular}{|c|c|}
\hline Atividades/objetivos & Lições aprendidas \\
\hline $\begin{array}{l}\text { Treinamento para o uso } \\
\text { do SL } \\
\text { Objetivos: capacitação básica } \\
\text { dos alunos para o uso da } \\
\text { tecnologia }\end{array}$ & $\begin{array}{l}\text { - A personalização do avatar (aparência, roupa, etc.) causa muito } \\
\text { interesse aos alunos e requer tempo; deve-se planejar carga horária } \\
\text { específica para isso; } \\
\text { - O treinamento mediado apenas por chat é mais lento e menos } \\
\text { produtivo, o pleno uso da tecnologia requer a disponibilidade de } \\
\text { vídeo e áudio; } \\
\text { - O ambiente do metaverso causa muita curiosidade e isso pode } \\
\text { gerar dispersão; o treinamento deve incluir exploração livre ou } \\
\text { guiada; } \\
\text { - As oscilações da Internet, a qualidade da conexão e do hardware } \\
\text { afetam o desempenho no metaverso, positiva e/ou negativamente; } \\
\text { - Há necessidade de adaptação nas capacitações realizadas nesse } \\
\text { tipo de ambiente, de forma a propiciar a familiarização com a } \\
\text { tecnologia. }\end{array}$ \\
\hline $\begin{array}{l}1^{\text {a }} \text { reunião } \\
\text { Objetivos: tema da palestra, } \\
\text { palestrante, convidados, } \\
\text { plano de ação e registro no } \\
\text { diário de aprendizagem. }\end{array}$ & $\begin{array}{l}\text { - O estímulo à interação dos alunos pelo professor mediador deve } \\
\text { ocorrer por intermédio de questionamentos e reflexões; } \\
\text { - A pauta das reuniões deve ser enxuta, pois as discussões podem } \\
\text { levar mais tempo que o previsto, em função de eventuais entraves } \\
\text { no acesso ao metaverso; } \\
\text { - Os processos grupais necessitam de bastante tempo para se } \\
\text { desenvolverem e não devem ser acelerados quando o objetivo é o } \\
\text { processo em si e não o resultado. }\end{array}$ \\
\hline
\end{tabular}


Atividades/objetivos

\section{$2^{\text {a }}$ reunião}

Objetivos: a definição

do palestrante, os

convites para o evento, o

acompanhamento do plano

de ação e o registro em

diário de aprendizagem.

\section{Lições aprendidas}

- A interação dos alunos se intensifica com base na integração entre os mesmos e o domínio da tecnologia, com pleno uso dos recursos;

- Na medida em que os alunos se integram, se sentem à vontade para expressarem suas opiniões, bem como respeitar as sugestões dos demais, começam a se preparar para trabalhar de forma conjunta; - O metaverso possui uma limitação parcial para o uso. por pessoas com necessidades especiais, como é o caso dos deficientes auditivos ou os visuais;

- Os alunos devem ser estimulados a interagirem no ambiente, além dos momentos obrigatórios, pois as funcionalidades são diversas; - O metaverso favorece que os alunos interajam entre si e com o ambiente como forma de intensificar os relacionamentos e gerar novos conhecimentos;

- Pode-se oferecer acesso às páginas da Internet, de dentro do próprio $S L$, permitindo o uso desse recurso sem precisar trabalhar com abas ou janelas abertas.

\section{$3^{\text {a }}$ reunião}

Objetivos: avaliação

e feedback do

desenvolvimento da competência para o trabalho em equipe.

\section{$4^{a}$ reunião}

Objetivos: convites, visita ao local do evento. Definição de responsabilidades.

\section{$5^{\text {a }}$ reunião}

Objetivos: Visita ao local do evento no $S L$ para verificar condições, melhorias etc., definição de responsabilidades no evento e combinações finais.
- O metaverso permite momentos de reflexão, avaliação e feedback; - No metaverso, além de disseminação de conteúdo, é possível desenvolver habilidades de forma prática e observação de atitudes, que colaborem para o desenvolvimento de competências;

- Como toda competência possui uma dimensão social, o metaverso colabora ao permitir a socialização.

- Os metaversos ainda não são reconhecidos popularmente como espaços educativos e de trabalho; isso dificulta a adesão de usuários voltados a atividades acadêmicas ou profissionais;

- Mesmo quando há um objetivo compartilhado entre um grupo de alunos, a noção de um propósito comum pode demorar a ser percebida.

- Fazer parte de uma equipe é desenvolver a capacidade de mobilizar os outros e a liderança pode se dar por meio da influência mútua; - O metaverso possui diversas possibilidades, mas nem sempre elas são percebidas como oportunidades de aprendizado;

- A possibilidade da simulação da realidade e até mesmo a extrapolação do que é real no metaverso dá materialidade aos planos desenvolvidos, causando a sensação de que algo foi feito, de fato, pois é possível visualizar e tocar o ambiente e seus objetos.

- O metaverso gera a sensação de presença, pois é possível aos participantes de uma reunião ou encontro lembrar-se de "quem estava lá", como a pessoa agiu, por onde andou, ações que realizou etc. 


\section{A REALIZAÇÃO DO EVENTO DE RECURSOS HUMANOS NO SECOND LIFE®}

O método de capacitação em si culminava com a realização do evento que os alunos foram desafiados a realizar em equipe. O evento ocorreu no dia 03 de dezembro de 20II, no SL, entre as I6 e ig horas e teve como palestrante o professor Dr. João Mattar, um dos maiores especialistas no Brasil sobre o uso do Second Life ${ }^{\circledR}$ na educação, discutindo sobre as possibilidades do metaverso para as diversas áreas do conhecimento, entre elas a gestão. Foram mediadoras da discussão quatro professoras do curso de RH da Unisinos.

O evento contou com 3I (trinta e um) avatares presentes, alguns deles

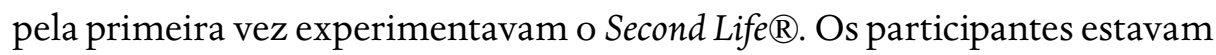
acessando o metaverso de diferentes localidades, como do Rio Grande do Sul, de São Paulo e até mesmo de Portugal.

Durante o evento, todos os recursos do ambiente funcionaram perfeitamente, inclusive o áudio, que costumava apresentar instabilidade. Houve apenas casos de avatares com os movimentos prejudicados, em função da baixa qualidade da conexão de Internet, ou mesmo por falta de prática do usuário.

De modo geral, o evento foi considerado um sucesso, inclusive as avaliações feitas nos totens ("Deixe aqui a sua opinião sobre o evento") indicaram um alto índice de satisfação dos participantes. Os resultados tabulados foram: 7I\% avaliaram o evento como "muito bom" e $29 \%$ como "bom". Nenhum dos votantes marcou a opção "a desejar" no objeto de avaliação.

O evento realizado pelos alunos representava o fechamento previsto no método de capacitação, restando apenas a participação dos mesmos na avaliação sobre a forma como essa atividade havia contribuído, ou não, para que desenvolvessem individualmente a sua competência para trabalhar em equipe. 


\section{AVALIAÇÃO DA APLICAÇÃO DO MÉTODO DE CAPACITAÇÃO (ARTEFATO)}

Além de captar a percepção dos alunos por intermédio do instrumento de autoavaliação da competência visada (reaplicado ao final da capacitação), os mesmos responderam a um questionário, com perguntas abertas sobre o método de capacitação e sobre o evento realizado.

Foram mencionados os seguintes pontos positivos: aprendizado; quebra de paradigma; descoberta de potencialidades do SL; realização de um evento de qualidade a distância; noção de presença/realidade; interações entre os participantes; desenvolvimento de competências individuais e coletivas. Os pontos a desejar, referentes ao método de capacitação, mencionados pelos alunos foram: pouco tempo para aprender a usar a tecnologia; horário dos encontros; problemas tecnológicos (acesso a hardware e software adequados); falhas na comunicação por áudio e baixa participação de alguns alunos.

Para captar a percepção das professoras, que foram as mediadoras no dia do evento realizado pelos alunos, foram marcadas entrevistas baseadas em um roteiro semiestruturado. Os aspectos positivos do evento observados pelas docentes foram: vivência diferenciada; forma agradável de aprendizado; quebra de paradigma por meio de evento virtual; mudança de raciocínio (do linear para o sistêmico); conteúdo da palestra enriquecedor e tratado com profundidade; qualidade das participações; evento com participações internacionais; noção de presença, sensações e emoções reais. Como aspectos a melhorar surgiram: mais tempo para discussão; incluir outros recursos audiovisuais como vídeos, por exemplo; dificuldades associadas à tecnologia utilizada pelos participantes (conexão da internet, software e hardware).

As percepções dos alunos e professores vão ao encontro do que aponta Waborton (2009) sobre a vivência no $S L$ : trazer inovação para a prática pedagógica ao estimular o entrosamento entre os indivíduos e objetos, e ao permitir a criação ou simulação de contextos que propiciam a imersão em um ambiente $3 \mathrm{D}$, onde a sensação de presença e pertencimento facilitam o compartilhamento de um propósito e o processo de ensino e aprendizagem. Também ratificam os achados de Andreas et al. (2010) sobre atividades em 
espaços educativos nos quais a interação via avatares pode complementar e/ou aumentar as interações face a face, melhorando abordagens em colaboração a distância e a comunicação entre os envolvidos.

Os aspectos a melhorar apontados na avaliação do método de capacitação também foram identificados por Waborton (2009), que menciona que a estrutura técnica é responsável pela qualidade da interação nos metaversos, mas que, ao mesmo tempo, pode ser uma de suas maiores fragilidades.

No que se refere ao desenvolvimento da competência individual para o trabalho em equipe, que é o foco deste estudo, os participantes perceberam que a tecnologia metaverso colabora nos seguintes aspectos:

- Construção de um contexto para o desenvolvimento da competência (construir o ambiente, criar cenários etc.);

- Simular situações que propiciem às pessoas planejarem e agirem (tomada de decisão e execução) e interagirem (atividades grupais);

- Proporcionar a aplicação de técnicas de gestão (planejamento, organização, direção e controle) e atividades práticas (operacionalização de tarefas);

- Desenvolver aspectos das relações interpessoais (comunicação, cooperação, gestão de conflitos, negociação etc.);

- Ampliar a sedimentação dos conteúdos por intermédio da preparação para a interação no ambiente;

- Complemento a atividades presenciais, especialmente ligadas à educação;

- Promover atividades em grupo mesmo à distância (jogos, brincadeiras, dinâmicas de grupo, reuniões de integração etc.).

A avaliação da aplicação do método de capacitação evidenciou que a principal contribuição do artefato concebido com o uso da tecnologia metaverso, para o desenvolvimento da competência para o trabalho em equipe, foi a criação de um contexto favorável para o desenvolvimento dessa competência baseado nas affordances percebidas pelos usuários.

Isso se faz relevante na medida em que, para Le Boterf (2003), as competências são sempre contextualizadas e evidenciadas por intermédio de ações; logo, o método de capacitação permitiu que, por meio da realização 
de atividades no metaverso, os alunos pudessem interagir e demonstrar evidências da competência investigada na prática.

A competência não preexiste, mas é construída pelo sujeito, ou seja, é um processo desenvolvido pelo profissional com base nos recursos possíveis (capacidades, conhecimentos, habilidades etc.), mas não se reduz a isso, envolve saber mobilizar, combinar e transformar (LE BOTERF, 2003). Buscou-se, portanto, desenvolver um método e um ambiente em que fosse possível aliar o contexto e a ação desejada, no qual se pudesse evidenciar e desenvolver as capacidades da competência individual de trabalho em equipe.

Outra contribuição do artefato foi a exploração das possibilidades que o metaverso oferece, principalmente em relação às affordances percebidas como educativas e que podem promover a aprendizagem colaborativa (ANDREAS et al., 20Io), tais como a interação, a noção de presença, a imersão, a visualização/contextualização.

O Quadro 4 demonstra como as principais affordances do metaverso podem colaborar para o desenvolvimento de competências, especialmente para a competência de trabalho em equipe. Relembra-se que, de acordo com Girvan e Savage (2010), affordances (do ponto de vista educacional) são as características de um artefato ou tecnologia que determinam se - e como - um comportamento particular de aprendizagem pode eventualmente ocorrer dentro de um determinado contexto. No Quadro 4 ponderam-se também as facilidades e dificuldades associadas a cada affordance.

Quadro 4 Síntese das affordances educacionais do metaverso para o desenvolvimento de competências (trabalho em equipe)

\begin{tabular}{|llll|}
\hline $\begin{array}{l}\text { Metaverso } \\
\text { Affordances }\end{array}$ & $\begin{array}{l}\text { Contribuição para o desenvolvimento } \\
\text { de competências (trabalho em equipe) }\end{array}$ & Dacilidades & Dificuldades \\
\hline Comunicação & $\begin{array}{l}\text { É possível se comunicar por intermédio } \\
\text { de texto, voz e imagem, incorporando }\end{array}$ & bastante similar a o áudio (voz \\
& elementos da comunicação não verbal, outras tecnologias sobre IP) fun- \\
& por meio dos gestos do avatar. Essa & (há familiaridade, ciona adequa- \\
& comunicação pode ocorrer de forma facilidade de uso) & damente. \\
& aberta ou privativa dentro do ambiente. &
\end{tabular}




\begin{tabular}{|c|c|c|c|}
\hline $\begin{array}{l}\text { Metaverso } \\
\text { Affordances }\end{array}$ & $\begin{array}{l}\text { Contribuição para o desenvolvimento } \\
\text { de competências (trabalho em equipe) }\end{array}$ & Facilidades & Dificuldades \\
\hline Movimentação & $\begin{array}{l}\text { Os movimentos disponíveis são andar, } \\
\text { correr, nadar, dançar, sentar, agachar, } \\
\text { deitar, pular, voar e ainda se teletranspor- } \\
\text { tar. Também há como incorporar gestos } \\
\text { (como sorrir, acenar e aplaudir) e movi- } \\
\text { mentos corporais ao avatar. }\end{array}$ & $\begin{array}{l}\text { Os movimentos } \\
\text { básicos são relati- } \\
\text { vamente fáceis de } \\
\text { utilizar, havendo } \\
\text { largura de banda e } \\
\text { hardware adequa- } \\
\text { dos. }\end{array}$ & $\begin{array}{l}\text { Nem todos os } \\
\text { gestos estão } \\
\text { disponíveis e é } \\
\text { mais complexo } \\
\text { saber usá-los de } \\
\text { forma conjunta } \\
\text { na comunicação. }\end{array}$ \\
\hline $\begin{array}{l}\text { Interação com } \\
\text { avatares }\end{array}$ & $\begin{array}{l}\text { Ocorre uma interação semelhante à que } \\
\text { se dá quando as pessoas interagem pes- } \\
\text { soalmente, ou seja, uma interação em } \\
\text { que há troca de informações, sentimen- } \\
\text { tos, emoções e percepção de compor- } \\
\text { tamentos. }\end{array}$ & $\begin{array}{l}\text { É possível interagir } \\
\text { com qualquer ava- } \\
\text { tar no ambiente. }\end{array}$ & $\begin{array}{l}\text { Há interações } \\
\text { indesejadas (ex: } \\
\text { interrupções } \\
\text { por visitantes) }\end{array}$ \\
\hline $\begin{array}{l}\text { Interação com o } \\
\text { ambiente }\end{array}$ & $\begin{array}{l}\text { O metaverso permite diversas interações } \\
\text { com os objetos e com o ambiente em si, } \\
\text { pois é possível "tocar" os objetos. Há a } \\
\text { possibilidade inclusive de se construir } \\
\text { objetos por meio de ferramenta disponí- } \\
\text { vel no metaverso. }\end{array}$ & $\begin{array}{l}\text { É possível "tocar" } \\
\text { e interagir com a } \\
\text { maioria dos obje- } \\
\text { tos. }\end{array}$ & $\begin{array}{l}\text { A construção de } \\
\text { objetos requer } \\
\text { conhecimento } \\
\text { especializado. }\end{array}$ \\
\hline Personalização & $\begin{array}{l}\text { O metaverso oferece diversas possibili- } \\
\text { dades no que se refere a personalizar o } \\
\text { avatar e o ambiente em si. }\end{array}$ & $\begin{array}{l}\text { A personalização } \\
\text { do avatar requer } \\
\text { aquisições para } \\
\text { o inventário ou a } \\
\text { busca de objetos } \\
\text { gratuitos. }\end{array}$ & $\begin{array}{l}\text { Como existem } \\
\text { diversas possi- } \\
\text { bilidades de per- } \\
\text { sonalização isso } \\
\text { requer tempo e } \\
\text { habilidade. }\end{array}$ \\
\hline Experimentação & $\begin{array}{l}\text { O medo do erro é minimizado em função } \\
\text { de os riscos serem baixos; isso permite } \\
\text { que algo seja feito tantas vezes quan- } \\
\text { tas forem necessárias. É possível que se } \\
\text { experimente aquilo que não se poderia } \\
\text { na vida real. }\end{array}$ & $\begin{array}{l}\text { A experimentação } \\
\text { é bastante intuitiva. }\end{array}$ & $\begin{array}{l}\text { Algumas pes- } \\
\text { soas resistem } \\
\text { em experimen- } \\
\text { tar tudo que o } \\
\text { metaverso pro- } \\
\text { porciona. }\end{array}$ \\
\hline Inovação & $\begin{array}{l}\text { A experimentação estimula a inovação, } \\
\text { pois como é possível fazer coisas consi- } \\
\text { deradas impossíveis ou de difícil aplica- } \\
\text { ção no mundo real, o metaverso torna-se } \\
\text { campo favorável para que se inove, como } \\
\text { por exemplo nos objetos e na arquitetura. }\end{array}$ & $\begin{array}{l}\text { A inovação se dá } \\
\text { principalmente } \\
\text { pela personaliza- } \\
\text { ção do avatar. }\end{array}$ & $\begin{array}{l}\text { A referência } \\
\text { para a inovação } \\
\text { ainda é a vida } \\
\text { real. }\end{array}$ \\
\hline
\end{tabular}




\begin{tabular}{|c|c|c|c|}
\hline $\begin{array}{l}\text { Metaverso } \\
\text { Affordances }\end{array}$ & $\begin{array}{l}\text { Contribuição para o desenvolvimento } \\
\text { de competências (trabalho em equipe) }\end{array}$ & Facilidades & Dificuldades \\
\hline $\begin{array}{l}\text { Interação } \\
\text { intercultural }\end{array}$ & $\begin{array}{l}\text { As interações com pessoas e lugares de } \\
\text { diferentes culturas são facilitadas, pois é } \\
\text { possível visitar qualquer lugar do mundo } \\
\text { sem necessidade de visto ou passaporte, } \\
\text { exceto no caso de poucas ilhas fechadas. }\end{array}$ & $\begin{array}{l}\text { Basta visitar ilhas } \\
\text { turísticas ou dos } \\
\text { próprios lugares } \\
\text { que de deseja } \\
\text { conhecer para inte- } \\
\text { ragir com diversas } \\
\text { culturas. Há um } \\
\text { recurso de tradu- } \\
\text { ção das conversas } \\
\text { para o idioma dese- } \\
\text { jado. }\end{array}$ & $\begin{array}{l}\text { A linguagem } \\
\text { acaba sendo } \\
\text { uma barreira, } \\
\text { pois alguns } \\
\text { avatares não } \\
\text { conseguem } \\
\text { estabelecer a } \\
\text { comunicação } \\
\text { em outros idio- } \\
\text { mas, mesmo } \\
\text { com o apoio de } \\
\text { tradução. }\end{array}$ \\
\hline Lúdica & $\begin{array}{l}\text { Os recursos lúdicos do metaverso vão } \\
\text { muito além de jogar, pois é possível ape- } \\
\text { nas brincar sem a noção de competição. } \\
\text { No Second Life, por exemplo, há muitos } \\
\text { locais destinados à diversão, cultura e ao } \\
\text { lazer. }\end{array}$ & $\begin{array}{l}\text { O ambiente em si } \\
\text { já remete ao lúdico. }\end{array}$ & $\begin{array}{l}\text { Por vezes, as } \\
\text { pessoas perce- } \\
\text { bem o meta- } \\
\text { verso apenas } \\
\text { como um jogo. }\end{array}$ \\
\hline $\begin{array}{l}\text { Noção de } \\
\text { presença }\end{array}$ & $\begin{array}{l}\text { É distintiva em relação a outras tecno- } \\
\text { logias utilizadas na EaD, pois a pessoa } \\
\text { realmente se "sente lá"; é a chamada pre- } \\
\text { sença por imersão. Com isso, o nível de } \\
\text { envolvimento, concentração e absorção } \\
\text { nas atividades é muito maior. }\end{array}$ & $\begin{array}{l}\text { É muito clara essa } \\
\text { percepção de estar } \\
\text { presente, todos os } \\
\text { participantes rela- } \\
\text { taram essa sensa- } \\
\text { ção. }\end{array}$ & $\begin{array}{l}\text { A noção de pre- } \\
\text { sença provoca } \\
\text { ansiedade em } \\
\text { relação à per- } \\
\text { sonalização do } \\
\text { avatar ("parecer } \\
\text { bem". }\end{array}$ \\
\hline $\begin{array}{l}\text { Sensações e } \\
\text { emoções }\end{array}$ & $\begin{array}{l}\text { Os participantes reportam sentimentos } \\
\text { compatíveis com uma vivência real; há } \\
\text { relatos de emoções positivas e negativas } \\
\text { como, por exemplo: medo, nervosismo, } \\
\text { ansiedade, vergonha, dúvida, superação, } \\
\text { alegria, afeição, surpresa, entre outras. }\end{array}$ & $\begin{array}{l}\text { As emoções enri- } \\
\text { quecem o apren- } \\
\text { dizado. }\end{array}$ & $\begin{array}{l}\text { Algumas emo- } \\
\text { ções podem } \\
\text { atrapalhar as ati- } \\
\text { vidades, assim } \\
\text { como na vida } \\
\text { real. }\end{array}$ \\
\hline $\begin{array}{l}\text { "Simulação" da } \\
\text { realidade }\end{array}$ & $\begin{array}{l}\text { O metaverso vai além da simulação; os } \\
\text { participantes percebem a experiência } \\
\text { dentro deles como real, servindo de } \\
\text { laboratório vivencial para a educação, o } \\
\text { treinamento e desenvolvimento. }\end{array}$ & $\begin{array}{l}\text { Facilita a criação de } \\
\text { um cenário apro- } \\
\text { priado ou mesmo } \\
\text { de uma situação } \\
\text { que se deseja testar. }\end{array}$ & $\begin{array}{l}\text { Alguns tipos } \\
\text { de simulação } \\
\text { requerem } \\
\text { o desenvol- } \\
\text { vimento de } \\
\text { objetos por } \\
\text { profissionais } \\
\text { especializados. }\end{array}$ \\
\hline
\end{tabular}

Por meio desse estudo, foi possível identificar as diversas affordances do metaverso, que contribuem para o desenvolvimento de competências, mais especificamente, a competência para o trabalho em equipe. O metaverso é capaz de proporcionar a ampliação das formas de comunicação virtual, 
permitindo que a EaD ocorra tanto de forma síncrona (os envolvidos estão conectados simultaneamente) ou assíncrona (a conexão ocorre em momentos distintos), além de favorecer o trabalho cooperativo/colaborativo, apesar de os envolvidos estarem distantes fisicamente (VALENTE; MATTAR, 2007). Isso ocorre por meio de diversos recursos para interação, não só por meio textual, mas por recursos que ampliam a percepção sensorial e o sentimento de imersão no ambiente.

Verificou-se que, dadas as diversas affordances do metaverso (Quadro 4), foi possível ir além de simplesmente simular situações de interação entre os alunos participantes do método de capacitação. O que foi feito não foi apenas uma simulação, foi real e percebido como tal, pois foi levado a sério pelos envolvidos. Assim, é possível utilizar o metaverso além da mera simulação e constituir um ambiente real de trabalho em equipe no qual se pode desenvolver as competências individuais para tal. Esse ambiente virtual possibilitou recursos para interação entre membros de uma equipe, recursos esses que não seriam possíveis nas tecnologias textuais da $\mathrm{EaD}$, como por exemplo, a noção de presença, memórias visuais dos participantes e do ambiente, personificação pelo uso de avatares, ambientes com recursos e objetos em 3 D etc. Nesses aspectos específicos, o metaverso (apesar das limitações técnicas eventualmente enfrentadas) mostrou-se superior a outras tecnologias de base textual utilizadas na educação a distância, oferecendo diferencial por meio de suas affordances educativas.

Outra affordance que merece destaque, por ser pouco explorada na literatura, é a de sensações e emoções percebidas durante a imersão no metaverso. Os participantes reportam sentimentos compatíveis com uma vivência real; há relatos de emoções positivas e negativas como, por exemplo: medo, nervosismo, ansiedade, vergonha, dúvida, superação, alegria, afeição, surpresa, entre outras. Considera-se que essa affordance é particularmente importante no que tange ao desenvolvimento de competências comportamentais, como a do trabalho em equipe, e também de diversas outras competências e atitudes importantes para a formação do administrador, como por exemplo, a competência para a resolução de conflitos, a resistência ao stress ou à pressão, a comunicação em público etc. 
Assim, os achados desta pesquisa indicam que o metaverso foi percebido como um espaço de vivência, no qual podem ser realizadas atividades em que os alunos vão experienciar diversas situações, para as quais terão que definir objetivos e fazer escolhas, ou seja, tomar decisões e agir para colocá-las em prática. Esse posicionamento é alicerçado em conhecimentos, que se converterão em habilidades e atitudes frente às situações-problema, formando uma base para o desenvolvimento de competências. 


\section{CONSIDERAÇÕES FINAIS}

O objetivo deste trabalho era identificar se (e como) o uso da tecnologia metaverso pode colaborar para o desenvolvimento da competência para o trabalho em equipe na educação a distância na Gestão de RH. Acreditavase que a principal contribuição do metaverso estava associada às suas affordances educativas, sendo que durante a pesquisa empírica isso se evidenciou, pois elas foram percebidas tanto pelos alunos, quanto pelos professores participantes do evento e pelos próprios pesquisadores.

Verificou-se que a tecnologia metaverso pode constituir-se como um ambiente, no qual é possível o desenvolvimento da competência individual investigada, ou seja, a do trabalho em equipe. Essa assertiva se sustenta tanto na percepção dos alunos participantes do método de capacitação, quanto na opinião dos professores, que atuaram como mediadores no evento de

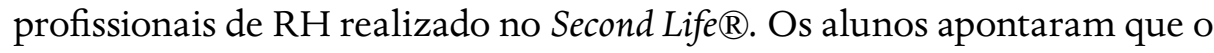
metaverso colabora para o desenvolvimento dessa competência na EaD na medida em que oferece complementos a essa modalidade de ensino como, por exemplo, a ampliação das formas de comunicação virtual e também por permitir uma interação significativa na educação mesmo à distância. Além disso, identificaram que o metaverso colabora na medida em que permite que se crie um contexto, no qual será possível trabalhar de forma sistêmica, de forma muito semelhante a contextos reais, e com uma identidade na forma de seu avatar, o que favorece a interação entre os participantes. Destacam que o metaverso dá a sensação de se estar vivenciando de fato uma experiência e isso contribui para a aprendizagem e o desenvolvimento de competências, entre elas a do trabalho em equipe.

Apesar de identificarem as contribuições do metaverso acima mencionadas, os participantes das atividades também reconheceram as limitações da tecnologia; entre elas, a eventual instabilidade da plataforma utilizada, a necessidade de acesso por computadores com alta capacidade de processamento, placa gráfica e conexão de banda larga, e também a possibilidade de distração, que o ambiente pode ocasionar, devido aos diversos estímulos que oferece. Há também a necessidade de treinamento 
apropriado para que os usuários explorem adequadamente todas as possibilidades oferecidas pela tecnologia.

Salienta-se que o Second Life $囚$ não tem a mesma popularidade de outras plataformas para redes sociais (por exemplo, o Facebook $\circledR$ ). A própria interação entre os alunos fora das reuniões de trabalho acabou ocorrendo via e-mail, o que denota que o $S L$ por si não basta como ferramenta de trabalho, precisa ser complementada por outras.

Outro ponto crítico relacionado ao metaverso utilizado refere-se à instabilidade do Second Life $囚$ em função de atualizações eventuais feitas por seus proprietários (Linden Lab). Percebeu-se que, quando a plataforma é atualizada, algumas funcionalidades podem perder momentaneamente a qualidade, principalmente a comunicação por áudio. Essa limitação não foi apontada nas referências encontradas na literatura sobre o uso de metaverso.

As principais limitações do estudo estão ligadas à complexidade do método em si, que envolveu a criação de um artefato. O método Design Research possui etapas bem detalhadas e complexas, ocasionando restrições temporais. Isso foi potencializado pelo tempo exíguo de que os alunos dispunham para participar da capacitação e para o que se propunha a estudar, ou seja, o desenvolvimento da competência para o trabalho em equipe. Também houve a limitação de se contar um único grupo de trabalho (com seis alunos voluntários), tendo em conta que, em uma turma normal de graduação, haveria várias equipes envolvidas. Essas são limitações desta pesquisa, que poderão ser superadas por estudos futuros, que repliquem o artefato criado (método de capacitação) ou testem um método semelhante.

Portanto, para futuros estudos sugere-se a realização de pesquisas acadêmicas similares, considerando (e procurando ampliar) as principais lições aprendidas durante esta pesquisa, de forma a identificar novas possibilidades no uso de metaversos para resultados mais eficazes no desenvolvimento da competência para o trabalho em equipe na EaD. 


\section{REFERÊNCIAS}

ANDREAS, K.; TSIATSOS, T.; TERZIDOU, T.; POMPORTSIS, A. Fostering collaborative learning in Second Life: Metaphors and affordances. Computers \& Education, v. 55, p. 603-615, 2010.

BAINBRIDGE, W. S. The Potential of Virtual Worlds. Science, v. 317, n. 5837, p. 472-476, 2007.

CENSOEAD.BR. ABED (Associação Brasileira de Educação a Distância). Edição Bilingue: português/inglês. São Paulo: Pearson Education do Brasil, 2011.

COLLINS, C. Looking to the Future: Higher Education in the Metaverse. EDUCAUSE Review, 2008.

CRESWELL, J.W. Projeto de pesquisa, métodos qualitativo, quantitativo e misto. Porto Alegre: Bookman, 2007.

ELLIS, A. P. J. An evaluation of generic teamwork skills training with action teams: effects on cognitive and skill-based outcomes. Personnel Psychology, v. 58, p. 641-672, 2005.

GIRVAN, C.; SAVAGE, T. Identifying an appropriate pedagogy for virtual worlds: A Communal Constructivism case study. Computers \& Education, v. 55, p. 342-349, 2010.

GRIFFIN, R.; MOORHEAD, G. Fundamentos do comportamento organizacional. São Paulo: Ática, 2006.

HERTEL, G.; KONRADT, U.; VOSS, K. Competencies for virtual teamwork: Development and validation of a web-based selection tool for members of distributed teams. European Journal of Work and Organizational Psychology, v. 15, n. 4, p. 477-504, 2006.

INEP. Instituto Nacional de Estudos e Pesquisas Educacionais Anísio Teixeira. Disponível em: < http://www.inep.gov.br/superior/censosuperior/sinopse/default.asp $>$. Acesso em: $18 / 04 / 2011$.

JEZERSKYTE், E.; ŽYDŽIÜNAITE், V. Comparing Teamwork Competencies of The School Administration and Educators: The Aspects of Groupthink (Avoidance) and Social Loafing. Social Sciences / Socialiniai Mokslai. Kaunas University of Technology, n.3, 2005.

KATZENBACH, J.R.; SMITH, D.K. The wisdow of teams: creating the high-performance organization. Boston: Harvard Business School Press, 1993.

LE BOTERF, G. Desenvolvendo a competência dos profissionais. Porto Alegre: Artmed, 2003.

LOMBARD, M.; DITTON, T. At the heart of it all: the concept of presence. Journal of Computer Mediated-Communication. Disponível em: <http://jcmc.indiana.edu/vol3/ issue2/lombard.html >. Acesso em: 05/01/2011. 
MARCH. S.; T. SMITH, G. F. Design and natural science research on information technology. Decision Support Systems, v. 15, p. 251-266, 1995.

MARGERISON, C.J.; McCANN, D. Gerenciamento de Equipes: novos enfoques práticos. São Paulo: Saraiva, 1996.

MILES, M.B.; HUBERMAN, A.M. Qualitative data analysis: an expanded sourcebook. 2.ed. Sage Publications, 1994.

MOSCOVICI, F. Equipes dão certo: a multiplicação do talento humano. 19. ed. Rio de Janeiro: José Olympio, 2008.

PARKER, G. M. Team players and team work: a nova estratégia competitiva. São Paulo: Pioneira, 1994.

O poder das equipes. Rio de Janeiro: Campus, 1995.

PARRY, S.B. The Quest for Competencies. Training and Development, v.33, n.7, p. 48-56, Jul. 1996.

PERRENOUD, P. Construir as competências desde a escola. Porto Alegre: Artes Médicas Sul, 1999.

PERRENOUD, P. Dez novas competências para ensinar. Porto Alegre: Artes Médicas Sul, 2000.

PERRENOUD, P.; THURLER, M. G. As competências para ensinar no século XXI: a formação dos professores e o desafio da avaliação. Porto Alegre: Artmed, 2002.

ROBBINS, H.; FINLEY, M. Por que as equipes não funcionam: o que deu certo e como torná-las criativas e eficientes. Rio de Janeiro: Campus, 1997.

ROBBINS, S. P. Administração: mudanças e perspectivas. 1.ed. São Paulo: Saraiva, 2009.

SCHLEMMER, E. Ambientes Virtuais de Aprendizagem. Porto Alegre: ArtMed, 2005.

SCHLEMMER, E.; BACKES, L. Metaversos: novos espaços para construção do conhecimento. Rev. Diálogo Educ., v.8, n. 24, p. 519-532, 2008.

SCHLEMMER, E.; TREIN, D.; OLIVEIRA, Christoffer. Metaverso: a telepresença em Mundos Digitais Virtuais 3D através do uso de avatares. In: SIMPÓSIO BRASILEIRO de INFORMÁTICA na EDUCAÇÃO (SBIE), 19., 2008, Fortaleza. Anais....Fortaleza [s.n.], 2008.1

STAGGERS, J.; GARCIA, S.; NAGELHOUT, E. Teamwork Through Team Building: Face-to-Face to Online. Business Communication Quarterly, v. 71, n. 4, p. 472-487, 2008.

STEYN, E.; STEYN, TFJ (Derik). The Challenge to Incorporate Teamwork as a Managerial Competency: The Case of Mainstream South African Newsrooms. Journal of Media Business Studies, 2009.

VAISHNAVI, V. KUECHLER, W. Design Research in Information Systems. January 20, 2005, last updated August 16, 2009. Disponível em: <http://desrist.org/design-researchin-information-systems $>$. Acesso em 28/12/2011. 
VALENTE, C.; MATTAR, J. Second Life e Web 2.0 na Educação: o potencial revolucionário das novas tecnologias. São Paulo: Novatec, 2007.

WABORTON, S. Second Life in higher education: assessing the potential for and the barriers to deploying virtual words in learning and teaching. British Journal of Education Technology, v. 40, n. 3, p. 414-426, 2009.

ZARIFIAN, P. Objetivo competência: por uma nova lógica. São Paulo: Atlas, 2001. 


\section{DADOS DOS AUTORES}

\section{ANA CLÁUDIA BILHÃO GOMES* anaconsultrh@gmail.com Mestre em Administração pela Unisinos \\ Instituição de vinculação: Universidade do Vale do Rio dos Sinos São Leopoldo/RS - Brasil}

Áreas de interesse em pesquisa: Administração, Gestão de Pessoas, Educação a Distância.

*Av. Unisinos, 950 Cristo Rei São Leopoldo/RS 93022-000

\section{AMAROLINDA ZANELA KLEIN amaroklein@gmail.com Doutora em Administração pela USP \\ Instituição de vinculação: Universidade do Vale do Rio dos Sinos São Leopoldo/RS - Brasil \\ Áreas de interesse em pesquisa: Administração e Sistemas de Informação.}

